\title{
Wind Power Generation Plant Addressing Which Based on WASP Software
}

\author{
Yujun $\mathrm{BAO}^{\mathrm{a},{ }^{*}}$, Yiming $\mathrm{HE}^{\mathrm{b}}$ \\ ${ }^{a}$ School of Electronic Information \& Electric Engineering, Changzhou Institute of Technology, CZU, \\ Changzhou, China \\ ${ }^{b}$ Changzhou Institute of Technology, CZU, Changzhou, China
}

\begin{abstract}
We have studied some basic problems about wind power generation plant addressing, such as the economy of wind power generation plant addressing, the affection of environment and wind power characteristics. We have analyzed and discussed seriously by comparing the steps about wind power generation plant addressing. In this paper, we also introduced the WASP software which used to how to address wind power generation plant.
\end{abstract}

Index Terms: Addressing of Wind Power Generation Plant; Economy; Wind Power Characteristics; WASP

Software

(C) 2011 Published by MECS Publisher. Selection and/or peer review under responsibility of the Research Association of Modern Education and Computer Science.

\section{Introduction}

Wind power generation plant addressing must be considered before build wind power generation, it is also the first key step in the whole wind power generation plant building, and it has relations with wind power generation plant's economical efficiency directly. Wind power generation plant addressing is similar to water power plant and nuclear power plant. On the other hand, it has a basic problem which is different from other generation plant addressing. To a wind power generation turbines, we can't evaluate its generation capacity and transient characteristic before the address has been confirmed. So it is impossible to estimate the cost of wind power generation.[1] Usually, the wind power conditions have relations with wind power turbines' generation capacity directly, and wind power is the main factor we must consider when we decide the wind power generation plant's address. In this paper, we have analyzed some basic problems about wind power generation plant addressing. And we also have introduced the WASP software which has been used widely.

\footnotetext{
* Corresponding author:

E-mail address: goldlake@163.com
} 


\section{Wind Power Generation Plant Addressing}

A good wind power generation plant should be economical, and it must meet the requirements of environment and the restriction of power dispatching. Wind power generation turbines should match the conditions of wind power, and we also consider the dynamic affection of power grid which caused by wind power generation turbines. Here, we have analyzed the problems about wind power generation plant addressing.

\subsection{Economy}

We should consider the wind power generation plant's economy efficiency before we start to build it. The wind power characteristics and the cost are all the main factors when we build wind power plant. The cost of kilowatt-hour turbine equipment is:

$$
1 k W h(\text { Cost })=\frac{\text { Cost of Equipment }}{\text { Power capacityin a year }} \operatorname{Yuan~} /(k W h)
$$

If we build wind power generation turbines which match the good position with plentiful wind power resources, the power generation capacity of a year can be increased greatly, which can reduce the cost of kilowatt-hour. So how to decide a best address with plentiful wind power resources is the main factor when we build a wind power generation plant.

The cost of equipment also can affect the economy efficiency of wind power generation plant. The whole cost includes the evaluation cost of addressing, the cost of wind power generation devices, the cost of devices' transportation, cost of labor used, and so on.[2]

\subsection{Affection of Environment}

Comparing with other forms of power generation, wind power generation has little effect on environment. But we have to consider the factor which can affect the wind power generation plant's environment. These effects mainly include three aspects: noise, electromagnetic interference and ecological environment.

- Noise: When wind power generation turbines operate, they always produce noise which is caused when air flows into vanes. The intensity of noise depends on the vanes' ending linear velocity and vanes' dynamical load. On the other hand, it also has relations with wind power turbines' type and the design of tower. So, when we design wind power turbines, we must consider the problems of noise. And we should try our best to reduce it.

- Electromagnetic interference: Electromagnetic interference is the potential environment problem which caused by wind power generation turbines. The rotational wind turbines' vanes can reflect electromagnetic wave which can affect television signal, radio guidance system and microwave transmission system. But we have little study on this aspect.

- Ecological environment: Wine power generation plant can has certain effect on the local weather and ecological environment, and this includes three aspects: The wind power generation plant can damage the earth and plants when we build it; The normal operating wind power generator can produce noise and radiation; Wind power generator can affect the local wind power characteristic. Some study shows that wind power generation plant has little the local weather, which can be ignored by comparing normal atmosphere changing. These two factors have little effect on environment, but the effect of wind power characteristics which caused by wind power generation plant is really great.[3] 


\subsection{Weather Factor}

When we decide the address, we should consider some weather conditions fully. These weather conditions can be represented by the item disaster. Some bad weather can damage wind power generator's structure, or increase maintenance cost, or shorten the equipments' operation period. Usually the main bad weather includes icing, typhoon, air salt-fog, and so on.

\subsection{Dynamic Effect}

Because the wind power generator's output varies greatly, and the varying time range from several seconds to several years. We should pay attention to the variation of sever seconds level or several minutes level, these kind of variations can have effect on normal generation equipments' transient stabilization, system power control and load current.[4]

\section{Addressing Step of Wind Power Generation Plant}

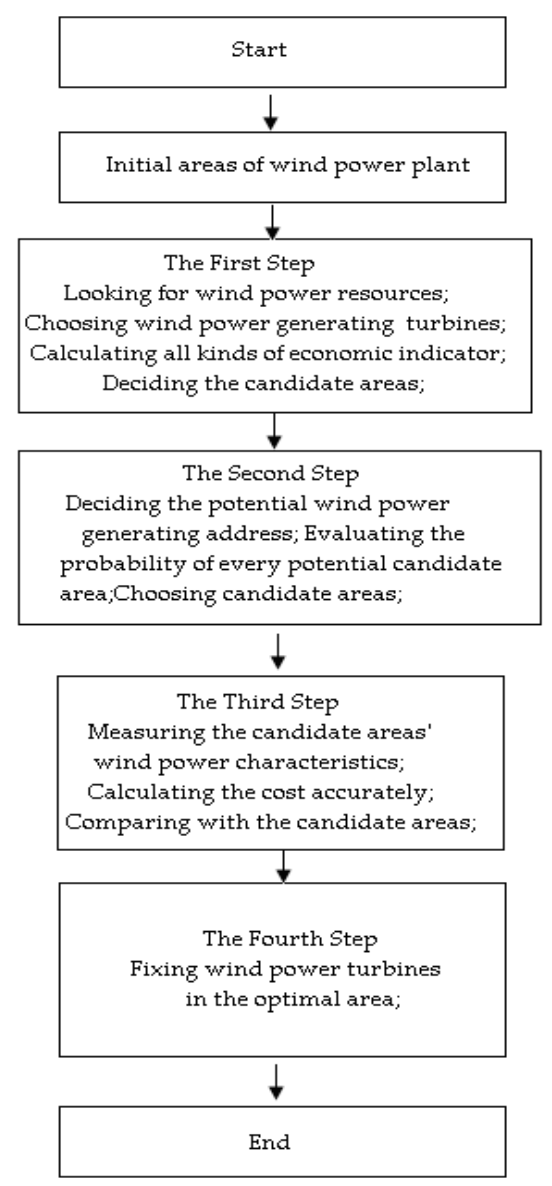

Fig. 1. Steps of wind power plant's addressing 
We can find that the addressing process of wind power plant is very complex by those analyses. We always hope that we can find a better way to get economical and useful wind power plant address. And we also hope that the way can be applied widely. On the basis of the study, we have concluded that there are five steps needed to ensure wind power plant's position. Fig.1 shows the flow:

\subsection{Candidate Wind Power Resource Area's Decision}

First, we should choose many better areas, and then we take some of these areas for the candidate areas. The so-called candidate wind power plant area is the area with proper area and better weather conditions. The scale of those candidate wind power resource areas are always different in the weather conditions, complexity of topographic and the data we have grasped. Once we have decided the best areas, we can compare these areas in accordance with one or several feasible probability values. We should gather the following data if we want to finish the first step well.[5]

- Current wind power resource data: these data always have been measured by some weather station or some other industries;

- Position of electric transmission lines: these data include the elected electric power system's voltage connection lines;

- Position of converter: these data include the position of converter and main connection lines. We also should know the probability of wind power plant's extension;

- Position of better ways: we should mainly consider the bridge's load bearing and semi-diameter;

- The restriction of local laws;

- The restrictions of geological conditions;

- The elected wind power equipments' normal technical performance;

- The cost of elected wind power equipment's fixion;

\subsection{The Choice of Potential Address}

The potential candidate wind power plant address is one of a small area in wind power resource. From the point of view of engineering, it is possible to fix wind power generation turbines in these areas. The main purpose of second step is to choose the best area form those potential wind power plant areas. We should consider wind power resource and the factors which have no relations with weather synthetically. The third step, we should compare with these two kinds of potential candidate addresses from the point of view of initial technical economical conditions. After a few candidate wind power plant areas are being chosen, we should measure wind power resources conditions in these candidate areas and acquire the wind power resources data. The measuring tower's height should be same with the actual wind power generation tower.

Usually, we use two kinds of methods. One is that we choose the best wind power resource area from those candidate areas. Then we choose the best one from the point of view of factors which have no relations with weather. Another is that we firstly choose the candidate wind power resources areas, and then choose the best one. At last, we should gather the following data:

- Data about measuring stations' positions of candidate wind power plant areas;

- Landform information of those candidate wind power plant areas;

- The required data which used to choose wind power plant;

- Some requirements about local laws or national laws;

- Side-effect which caused by the building of wind power turbines;

- Geological map of the candidate wind power plant's area;

- The isolated area which can avoid the personal injury which caused by wind power turbines' fragments;

- Positions of converter and electric power transmission lines;

- The probable environment effect; 
- Analyzing data about wind power plant's operation performance and total cost;

- The needed total cost of wind power plant's fixing, operating and maintaining;

- The candidate areas' detailed characteristics, such as landform, characteristics of the earth's surface, irregularity degree of earth's surface, and the conditions of wind power characteristic and weather.

\subsection{Choosing the Optimal Address}

The third step is that we choose the optimal area from the candidate wind power plant areas. Its main purpose includes:

- Gathering the accurate wind power information from every wind power plant area, this can help us to evaluate the wind power turbines' electric power generation capacity precisely;

- Evaluating every area's economical value;

- Confirming the probable effect which caused by wind power turbines;

- Ensuring wind resources' characteristics to match the design of wind power generator's service life;

- Evaluating the probable environment effect which caused by wind power generation turbines;

The needed data in the third step include:

- The needed weather data about simulating generation process;

- The needed all kinds of environment and social which meet the requirements when we choose address;

- The needed all kinds of engineering data which used to design a whole wind power generation plant;

- The needed all kinds of data which used to evaluate the cost of building a wind power generation plant;

- The needed non-weather data which used to process production cost model;

- The considered wind power turbines' performance and operating strategy;

- The probable weather disaster information;

In this step, the key process is gathering filed data, which has relations with economical development directly. So, it is necessary to choose a better wind speed measuring meter, and its height is same with wind power generator tower. After recalculating the economical efficiency, we can choose the optimal address.[6]

\subsection{Fixing Wind Power Generation Equipment in the Chosen Area}

After confirming the optimal area, the fourth step is that we can fix wind power generation equipments designedly and in batches. We can build wind power plant right now if all kinds of conditions have been satisfied.

\section{WASP Software}

The most important problem in these analyses is that the evaluation of wind power resources and wind power generation turbines' distribution. And we always process plentiful original data when we evaluate wind power resources. This is a very difficult process if we only depend on manual methods. If we depend on computer by means of some processing software, we can make it much easier to choose optimal wind power plant.

\subsection{Thoughts of WASP Software}

First, we can build mathematical model by means of one area's wind speed data and wind direction data when we use WASP software. And then we don't need to consider the effect which caused by landform, earth surface and shelter object on wind power resources, so we can get the wind's distribution rules at the standard 
conditions of normal wind power, which is called wind map. Wind map shows the wind speed's probability distribution under the standard conditions, and it meets Weibull distribution basically.[7] Then we calculate the measured-point's average wind speed and average wind power density by considering the effect which caused by such factors as landform and earth surface condition on the basis of wind map. And we can calculate the theoretical electric power capacity if we consider wind power turbines' power characteristic curve.

\subsection{WASP Software's Basic Functions}

WASP software has four basic functions:

Analyzing original data: it can convert the original data into histogram which is weather data's input of WASP. The original data can be analyzed by means of Weibull distribution parameters. WASP can classify the input wind speed and direction data by defining bound. Wind speed can be classified four levels: calm wind, breeze, overrun wind and reading error.

Generating wind map data: the histogram which represents wind speed can be converted into wind map data diagram. We needn't consider the effect of landform, earth surface, and so on.[8]

Evaluating wind power turbine's power: we can calculate wind power turbine's theoretical electric power capacity on the basis of wind map.

\subsection{WASP Software's Basic Structure}

WASP software is mainly constructed by menu structure. Fig.2 shows this sutructue. It includes primary menu, current state display and other submenus which are from the main menu. All the menus have their own key word which can be chosen in accordance with the practical need. On the other hand, WASP has the function that it can enter system without ending itself, which can provide field guide for users.

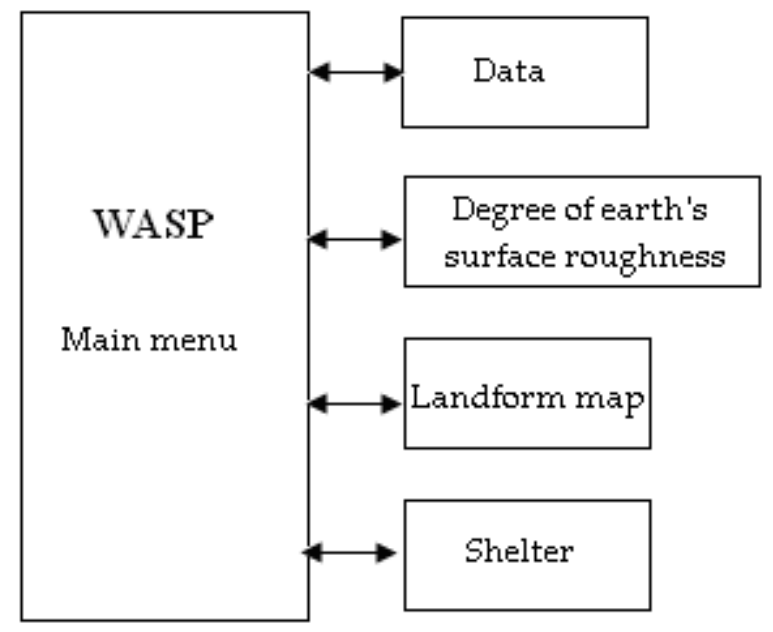

Fig. 2. Basic block diagram of WASP software's menu 


\section{Conclusions}

Wind power generation plant's addressing is the first important step when we start to build wind power plant. And we can build mathematical model by means of one area's wind speed data and wind direction data when we use WASP software. Then we don't need to consider the effect which caused by landform, earth surface and shelter object on wind power resources, so we can get the wind's distribution rules at the standard conditions of normal wind power, which is called wind map. Wind map shows the wind speed's probability distribution under the standard conditions, and it meets Weibull distribution basically. Then we calculate the measuredpoint's average wind speed and average wind power density by considering the effect which caused by such factors as landform and earth surface condition on the basis of wind map. And we can calculate the theoretical electric power capacity if we consider wind power turbines' power characteristic curve. This can be used as rules when we choose wind power plant's address, and it also can provide field guide for users.

\section{Acknowledgements}

We are very grateful to the Jiangsu Province College Natural Science Foundation of China for the support.

\section{References}

[1] LUO Wei-wei, Direct Power Control System Strategy Based on Stator Resistance Compensation[J], LARGE ELECTRIC MACHINE AND HYDRAULIC TURBINE, 2009(3)

[2] ZANG Liang YU Ke-xun, The control of doubly-fed generator in the wind energy conversion system[J], ELECTRICAL APPLIANCES, 2006(5)

[3] Tian Jiwei, Zhang Xinyan, Simulation of the Voltage Pulsation of the Power Grid Caused by the Integration with the Wind Farm[J], ELECTRICAL MACHINERY TECHNOLOGY, 2008(5)

[4] Zhang Xiaobo, Zhang Xinyan, Fault Analysis of Power Electronic Devices in Wind Power System by Means of Wavelet Analysis[J], ELECTRICAL MACHINERY TECHNOLOGY, 2008(5)

[5] ZHANG Yue, Performance research on permanent magnet synchronous generator directly driven by wind turbine[J], ELECTRIC MACHINES AND CONTROL, 2009 13(1)

[6] FANG Min, JIN Chunpeng, Investigating Large Scale Non-Grid-Connected Wind Power Industry System[J], RESOURCES SCIENCE, 2009 31(11)

[7] LIU Yong, KONG Xiangwei, A Perspective Study on Technical Support System for Building Large Scale Offshore Wind Farm[J], RESOURCES SCIENCE, 2009 31(11)

[8] LIU Xue-jing, WANG Wei, Simulation of Control Strategy of Wind Turbine with Permanent Magnet(PM) Generator[J], COMPUTER SIMULATION, 2009 26(3) 